DOI: http://dx.doi.org/10.22483/2177-5796.2017v19n1p47-68

\title{
História da implantação da Escola Rural de Xaxim (1952-1961) no contexto da escolarização do oeste Paranaense
}

\author{
Francielle Aparecida Garuti de Andrade \\ Cézar de Alencar Arnaut de Toledo
}

Resumo: O objeto desta pesquisa é a Escola de Xaxim, uma instituição escolar rural, criada no ano de 1952, no Povoado de Xaxim, área rural de Toledo, no oeste paranaense. A escola foi criada mediante um acordo celebrado entre o estado do Paraná e o Governo Municipal de Foz do Iguaçu, Comarca de Toledo, e visava atender aos filhos dos trabalhadores que residiam naquela localidade. Trata-se de um estudo histórico e documental sobre a implantação da escola. A pesquisa está situada no campo da história e historiografia das instituições escolares. Sua realização se deu por meio da análise de documentos que descrevem a trajetória da instituição. Para a efetivação da pesquisa foram utilizadas fontes disponíveis no acervo do Museu Willy Barth, de Toledo, PR.

Palavras-chave: História da educação. Instituições escolares. Região oeste do Paraná. Escola Rural de Xaxim.

\section{History of the implementation Xaxim rural school (1952-1961) in the context of Paranaense west schooling}

\begin{abstract}
The object of this research is the Xaxim's School, a rural school institution, created in 1952, in the town of Xaxim, Toledo's rural area, in the far west of Paraná. At that time, the school was created by an agreement between the state of Paraná and the Municipal Government of Foz do Iguaçu, Toledo's District, and was intended to meet the children of workers who lived in that area. It is a historical and documentary study on the school roll. The research issituated in the study field of history and historiography of educational institutions. This achievement was through the analysis of documents that describe the institution's trajectory. This research used documents available in Willy Barth Museum of Toledo city.
\end{abstract}

Keywords: History of education. Educational institutions. West Paraná region. Xaxim rural school.

Quaestio, Sorocaba, SP, v. 19, n. 1, p. 47-68, abr. 2017. 


\section{Introdução}

Este texto tem por objetivo analisar a história da implantação da Escola Rural de Xaxim, instituição pública, localizada no Povoado de Xaxim, localidade da área rural de Toledo, no extremo oeste paranaense, fundada no ano de 1952 mediante um convênio entre o Estado do Paraná e a Prefeitura municipal de Foz do Iguaçu. Quando da fundação da escola, a localidade de Xaxim fazia parte de uma importante rota de comércio da região que ligava o recém-formado distrito de Toledo ao Porto Britânia, local de onde os cereais e a madeira eram escoados para a Argentina, Paraguai e para outros estados brasileiros. Essa foi a primeira estrada que a Industrial Madeireira Colonizadora Rio Paraná S/A, empresa privada responsável pela colonização de uma parte do oeste do paranaense, abriu na região. O povoado de Xaxim distava aproximadamente cinco quilômetros do núcleo urbano de Toledo (SECRETARIA MUNICIPAL DE EDUCAÇÃO E CULTURA DE FOZ DO IGUAÇU, 1952).

As atividades escolares foram iniciadas com 21 alunos sob a regência da professora Vilma Cerutti e duraram até o início da década de 1960, período em que as atividades do Porto Britânia já tinham sido encerradas e o fluxo de pessoas na localidade diminuído (NIEDERAUER, 2004). Na década de 1960, após o fortalecimento do núcleo urbano de Toledo e o êxodo rural em toda região oeste do Paraná, a demanda escolar nas localidades rurais diminuiu. Com base na documentação disponível, pode-se dizer que após esse período a escola encerrou suas atividades.

A pesquisa foi realizada mediante a análise de documentos que descrevem o processo de implantação da escola; para sua efetivação foram utilizadas fontes como: Livros-ata de Exames Finais; Documento da Diretoria Geral da Educação de contratação da professora; Boletim Mensal da Secretaria de Educação e Cultura de Foz do Iguaçu; Fotos da escola da década de 1950; todos disponíveis no acervo do Museu Histórico Willy Barth, de Toledo, PR.

Para discutir a temática proposta, inicialmente será analisada a pesquisa sobre instituições escolares e a importância das fontes para realização dessas pesquisas. Em seguida, será estudada a colonização e a escolarização da região oeste do Paraná no período da criação da Escola Rural de Xaxim (1950-1960). Posteriormente será discutida a questão da educação rural no Brasil e no oeste paranaense. Por fim, será abordada a implantação da Escola Rural de Xaxim. Serão analisados alguns elementos que constituem a história das instituições educativas, a saber: corpo docente, corpo discente, prédio escolar e currículo. 
Entendemos como importante a investigação de uma instituição educacional regional, porque o estudo da história local permite reconstituir as intencionalidades e interesses que nortearam seu processo de criação e consolidação. Ao realizar o trabalho de reconstituição histórica das instituições educacionais, contribuímos para a preservação da memória educacional da região e para a valorização do patrimônio cultural.

\section{Instituições escolares no contexto da História da Educação}

Atualmente, a temática da escola tem sido recorrente na área da História da Educação. Abordada sob as diversas perspectivas de informação e análise, a historiografia da escola vem sendo ampliada e renovada. Nos últimos anos multiplicaram-se os olhares sobre a especificidade (cultura escolar, pedagogia, arquitetura, mobiliário, materiais didáticos, artefatos, disposição espacial); diversificaram-se estudos comparativos de amplitude territorial (local, regional, nacional, federal); foram revigorados parâmetros e perspectivas sobre mundialização e globalização do processo e do modelo didático-pedagógicos escolares (MAGALHÃES, 2010).

A análise da história das instituições escolares no Brasil tem se firmado como uma Linha de Pesquisa no âmbito da História da Educação e constituído cada vez mais, num campo de investigação promissor (NOSELLA; BUFFA, 2009). Trata-se de uma linha de pesquisa no contexto da História da Educação, que se ocupa em descrever seus protagonistas em suas ações, bem como, os diferentes momentos vividos pela instituição educativa, suas contradições, sua estrutura física, sua relação com as políticas educacionais, seu projeto pedagógico e outros temas que contribuem com a compreensão do fenômeno histórico-educativo em sua totalidade. Magalhães (1998, p. 57) afirma que:

A partir das ciências da educação, a história da educação, focalizada na escola, tem procurado corresponder a um núcleo duro de questões trans e interdisciplinares, definindo e consolidando o seu estatuto epistêmico através do contributo para os debates centrais às ciências da educação.

Um dos elementos motivadores para as investigações sobre essa área temática é a possibilidade de se escrever a História da Educação brasileira e regional sob um prisma diferente daquele que dá espaço apenas às narrativas emanadas de documentos oficiais. Essa linha de investigação tem se consolidado como uma proposta de pesquisa que visa à valorização das 
peculiaridades regionais, sem desconsiderar as dimensões nacionais; entende-se que, ao analisar as características de uma determinada instituição, espacial e geograficamente determinada, nasce a possibilidade de conhecer o contexto histórico-político e social que a criou (ARNAUT DE TOLEDO; ANDRADE, 2013).

A temática que contempla o estudo da história e da historiografia das instituições educativas se insere no contexto de ampliação do número de novos objetos que têm sido analisados a partir de sua historicidade. Dentre os novos temas, destacam-se: instituições escolares, práticas educativas, políticas educacionais, educação rural, educação indígena, educação especial, educação a distância, entre outros. Apesar das dificuldades, devido à inexistência de repertórios de fontes organizados, muitos historiadores da educação no Brasil têm se lançado na tarefa de historiar a educação escolar brasileira por meio da construção de interpretações acerca das principais instituições espalhadas pelas diversas regiões brasileiras (GATTI JR., 2002).

O estudo da história das instituições escolares, conforme propõe Paulo Nosella e Ester Buffa (2012), além de descrever a vida e os fatos que ocorreram no interior da escola, não fica preso apenas nos relatos históricos lineares sobre seu dia a dia. Tais pesquisas devem levar o leitor à compreensão da totalidade histórica.

Assim, historiar uma instituição educativa é investigar o que se passa em seu interior, a partir da análise que envolve os vários atores participantes do processo educativo, à luz do contexto geral, pois o movimento em seu interior reflete, de maneira particular e elaborada, o movimento social onde a instituição está inserida; a escola, portanto, deve ser analisada à luz de seu contexto histórico, social e político (NOSELLA; BUFFA, 2009).

Cada instituição, escolar ou não, faz parte do todo social, de uma rede de complexos, de múltiplas determinações que forma um sistema societário integral e em constante transformação, sendo produzida pelo movimento histórico formado com base na luta entre elementos societários contraditórios; todavia, ela possui elementos internos que a diferem de outras instituições, fazendo-a única e que são revelados através da singularidade (FERREIRA JR.; BITTAR, 2008).

A compreensão da instituição escolar como produto da ação do homem na história, que cria as instituições para atender a determinadas necessidades suas, está ancorada na proposta metodológica do materialismo histórico elaborada por Karl Marx (1818-1883) e Friedrich Engels 
(1820-1895). Na percepção desses autores, o homem, enquanto sujeito real e que vive numa realidade material, produz sua historicidade a partir das condições materiais que lhe são dadas pela natureza, pelas suas necessidades e pelas novas relações que estabelece com o mundo e com os outros homens (MARX; ENGELS, 1993).

Nesse sentido, a compreensão de uma instituição passa, necessariamente, por uma análise da totalidade, enquanto o singular, no caso, a escola, não existe por si, pois está contido no universal e o universal, por sua vez, está envolto nas contradições das múltiplas singularidades. Sendo assim, o estudo das instituições escolares contribui para a construção de conhecimentos históricos e também para a reconstituição da história da educação (LOMBARDI, 2011).

A investigação de um objeto, com base nas categorias de análise que Marx e Engels propuseram, oferece o suporte necessário para a discussão da realidade histórica. Um pesquisador deve buscar investigar e interpretar os dados com a finalidade de apreender seu significado real, histórico e material. Ou seja, da análise das características pertinentes à instituição, nascerá a possibilidade de conhecer o que lhe atribuiu sentido no cenário social do qual fez ou ainda faz parte. O desafio é apresentar ao leitor a totalidade histórica, para tanto, tem de ser considerada a relação entre a escola e a sociedade que a produziu, pois ela é influenciada pela sociedade e influencia a sociedade onde está inserida (SANFELICE, 2007).

Ao propor investigar a história e a historiografia das instituições educacionais, o pesquisador deve seguir um plano de pesquisa que esteja pautado em categorias de análise que permitam traçar um retrato da instituição com seus atores, aspectos de sua organização, seu cotidiano, seus rituais, sua cultura e seu significado para a sociedade concernente ao recorte temporal proposto na pesquisa.

Os historiadores da educação, Paolo Nosella e Ester Buffa (2009), propõem algumas categorias, notoriamente ancoradas na teoria marxiana, que podem servir de parâmetro para os pesquisadores na realização dessas pesquisas, a saber: o contexto histórico da criação e da instalação da escola; seu processo evolutivo: origens, apogeu e situação atual; o cotidiano escolar; o prédio e infraestrutura escolar: organização do espaço, estilo, acabamento, implantação, reformas e eventuais descaracterizações; corpo discente: origem social, destino profissional e suas organizações; corpo docente e equipe pedagógica: origem, formação, atuação e organização; organização pedagógica: currículo, disciplinas, livros didáticos, métodos e 
instrumentos de ensino; práticas disciplinares: regimentos, organização do poder, burocracia, prêmios e castigos; eventos: festas, exposições, desfiles.

Nesta perspectiva, analisar a história de uma instituição educativa possibilita ao pesquisador, e à própria comunidade escolar, entender os enlaces que cercaram ou cercam tal instituição para desvendar, desta forma, seus papéis na sociedade.

\subsection{Fontes e pesquisa sobre instituições escolares}

Essa linha de investigação possui caráter histórico/documental e contempla o levantamento e a análise de documentos. A reconstituição histórica das instituições educacionais, como objeto de análise da História da Educação, exige o uso de fontes que, por sua vez, são a base sobre a qual se constrói uma pesquisa, onde se apoia a construção historiográfica, que é a reconstrução, no plano do conhecimento, do objeto histórico estudado. As fontes são, portanto, a matéria prima na construção da pesquisa (SAVIANI, 2004).

A palavra fonte, segundo o dicionário eletrônico Houaiss, pode ser definida como: "texto ou documento original". As fontes são registros, documentos, marcas e vestígios deixados por indivíduos, por grupos, pelas sociedades e pela natureza que representam ou expressam uma determinada forma de ser da matéria, seja ela natural, humana ou social, em seu processo de contradição e transformação (RAGAZZINI, 2001). Elas são produzidas pelo homem nas suas relações sociais e com a natureza, resultam, portanto, da ação histórica dos indivíduos e registram seu modo de vida em suas relações numa determinada sociedade. Para Júlio Aróstegui (2006, p. 491), fonte histórica é "todo material, instrumento ou ferramenta, símbolo ou discurso intelectual, que procede da criatividade humana, através do qual se pode inferir algo acerca de uma determinada situação social no tempo".

Nas áreas da História e da História da Educação, o conceito de fontes tem passado por uma modificação e ampliação nas últimas décadas. A discussão sobre o emprego de fontes escritas, sonoras, audiovisuais, pictóricas, entre outras, como elementos que possibilitem o entendimento do passado entrou na pauta da historiografia da educação e abriu precedente para a discussão do que poderia ser considerada fonte para a pesquisa historiográfica. Por muito tempo, fontes históricas se resumiam a documentos oficiais, por isso, a história só existia como expressão do Estado. 
A ampliação da noção de fonte resulta, em grande medida, da inserção de novos objetos que passaram a ser investigados em sua historicidade. Com tamanha vastidão de novas temáticas na área da História da Educação, a noção do que pode ser considerado documento histórico sofreu significava modificação. Renovou-se o conceito de fontes ${ }^{1}$. Não há nas fontes verdade absoluta, pois elas carregam em si marcas humanas que são passíveis de múltiplas interpretações, assim, as pistas, os vestígios, os documentos, são fragmentos que não possuem uma verdade inerente, pronta a ser desvelada pelo pesquisador, mas, depende dos questionamentos que o investigador faz e carece de interpretação. De acordo com Jaques Le Goff, "nenhum documento é inocente. Deve ser analisado. Todo documento é um monumento que deve ser des-estruturado, des-montado" (LE GOFF, 2003, p. 110), pois, ele é produto da sociedade que o fabricou segundo as relações de forças que detinham o poder.

Pode-se dizer que na História da Educação surgiu uma preocupação que tem sido amplamente difundida entre os pesquisadores da área e que prevê uma formação adequada para o trabalho com as novas fontes. Ao incluir entre as fontes históricas, outros materiais da documentação manuscrita e impressa (atas, normas, regulamentos, programas), para as quais já se tinha procedimentos de tratamento sedimentados, surgiu a necessidade de conhecimento e domínio de outros procedimentos de análise dessas novas fontes, que visa garantir a qualidade da interpretação a partir de procedimentos de investigação ancorados num rigoroso tratamento dos documentos.

\section{Colonização e escolarização na região oeste do Paraná no período da criação da Escola Rural de Xaxim (1940-1960)}

A região oeste do Paraná viveu vários períodos em seu processo de colonização ${ }^{2}$. Esse fato se deve, sobretudo, à sua localização em área de fronteira. A região faz fronteira com

\footnotetext{
${ }^{1}$ A escola dos Annales, movimento francês de renovação da historiografia dos anos de 1920, ao propor um alargamento do conceito de fontes e o uso de documentos não oficiais para elaboração historiográfica indicou um novo rumo para o uso de fontes em pesquisas históricas. A renovação do conceito do que são Fontes Históricas representou uma espécie de ruptura com a Historiografia Tradicional. Ao propor a expansão das fontes e o uso de documentos não oficiais, os Annales valorizaram a ação coletiva e individual, geral e particular dos indivíduos. O movimento contribuiu para a ampliação da noção de documento, não mais só os escritos, mas a tudo aquilo que revela o passado humano, que é fruto da ação do homem, nos seus mais diversos suportes. Embora os documentos escritos continuassem compondo a maior parte das fontes históricas abriu-se a possibilidade de novas fontes serem incorporadas à pesquisa histórica (NOSELLA; BUFFA, 2009).

${ }^{2} \mathrm{O}$ significado do conceito de colonização muda no tempo e no espaço. $\mathrm{O}$ ato de colonizar está diretamente Quaestio, Sorocaba, SP, v. 19, n. 1, p. 47-68, abr. 2017.
} 
Argentina e Paraguai. Segundo Ruy Wachowicz (2001, p. 233), o oeste paranaense pode ser assim delimitado: "território compreendido entre os rios Guarani, Iguaçu, Paraná e Piquiri”.

Até o final do século XIX e início do XX, o oeste do Paraná era pouco explorado. A despeito da presença indígena na região, pouco havia de exploração das riquezas naturais. Esse cenário mudou na medida em que companhias argentinas e inglesas se radicaram nessas terras, dando início à extração da madeira, da erva-mate e de outros produtos nativos. A ocupação não foi desarticulada da colonização das demais regiões do estado. Grande parte dos documentos oficiais sobre história do Paraná difunde a ideia de que os territórios do oeste paranaense, antes de sua colonização planejada, estavam totalmente desocupados e que havia um "vazio demográfico". Essa leitura, entretanto, conflui para os interesses do empresariado nacional, que via a possiblidade de incorporar essas "novas terras" do território paranaense ao sistema de produção capitalista, que, à época da ocupação, estava em franca expansão (WACHOWICZ, 1982).

A colonização da região se deu entre os anos de 1940 e 1960 e recebeu direta influência das transformações sociais, científicas e tecnológicas que estavam ocorrendo no Brasil naquele momento. A chegada de colonos do sudoeste do estado e posteriormente, de colonos descendentes de alemães e italianos, provenientes do norte do Rio Grande do Sul e do oeste de Santa Catarina, constituiu-se na ocupação recente do oeste paranaense, mediado pela atuação de empresas colonizadoras de capital privado.

Essas companhias tinham larga experiência em empreendimentos colonizatórios em outros estados da região Sul do Brasil e firmaram acordos com o governo paranaense para explorar a terra e vender propriedades em várias localidades do estado, incluindo a região oeste. O estado do Paraná abdicou da possível arrecadação de impostos com a venda de lotes rurais e urbanos e passou o ônus da infraestrutura mínima para a iniciativa privada (GREGORY, 2005).

O modelo de colonização desenvolvido na região foi racional e intensivo e esteve alicerçado na pequena propriedade. As oligarquias tradicionais e a burguesia estadual emergente

relacionado às questões políticas, sociais e econômicas; pois no processo de colonização existem diferentes interesses envolvidos. Trata-se de um ato político, de uma forma de produção social complexa. O ato de colonizar, num primeiro momento, denota deslocamento em que os agentes fazem de seu mundo para outro onde irão exercer a capacidade de lavrar ou fazer lavrar. Alfredo Bosi enfatiza que o processo de colonização "[...] consiste em um projeto totalizante cujas forças motrizes poderão sempre buscar-se ao nível do solo: ocupar um novo chão, explorar seus bens" (BOSI, 1992, p. 12). 
tinham interesses em comum no processo de colonização da região. O programa do Governo Federal denominado "Marcha para o Oeste" fez convergir os interesses de ambos, que focalizavam o acúmulo de mais capital; assim, os governos federal e estadual e o capital privado das colonizadoras uniram seus interesses no processo de colonização planejada do oeste. As empresas colonizadoras coordenaram o processo visando à ampliação de seu capital. Por meio da venda de terras, as companhias atuaram intensamente no oeste do Paraná (GREGORY, 2005).

Dentre as empresas colonizadoras que atuaram no oeste do Paraná, destacou-se a MARIPA - Industrial Madeireira Colonizadora Rio Paraná S/A, que coordenou a ocupação da região onde está localizado o município de Toledo, por meio da exploração das riquezas naturais e da prática de negócios imobiliários. Todo processo de ocupação e colonização do oeste paranaense não se deu isoladamente, mas fez parte de uma conjuntura histórica que o favoreceu, ou seja, não esteve desassociado do contexto político-econômico nacional e internacional (SCHNEIDER, 2001).

O processo de escolarização no oeste paranaense e no município de Toledo ocorreu simultaneamente as transformações sociais desencadeadas no panorama histórico estadual e nacional. Compreendeu distintos modos de instrução ao longo da colonização e, de acordo com os interesses políticos e econômicos postos em disputa no período pelos diferentes grupos sociais: colonos, agricultores, imigrantes europeus, latifundiários ou outros segmentos. A escolarização da região esteve intimamente associada ao processo de ocupação. Segundo Ivo Oss Emer (1991), a escolarização da região passou por quatro fases distintas, a saber: escolarização Particular Domiciliar; Casa Escolar Particular; Casa Escolar Pública e Grupo Escolar.

Podemos dizer que a origem da educação escolar no oeste do Paraná esteve associada à presença dos migrantes e a forma como culturalmente se organizaram em torno da escola. No munícipio de Toledo, a escola se constituiu a partir da iniciativa privada, sobretudo, por meio da criação de escolas confessionais, construídas ao lado das igrejas, que muitas vezes serviram de escolas ou vice-versa. Durante os anos de 1950/1960 houve um significativo avanço na escolarização e construção de escolas no município. Neste período a região começou a definir sua estrutura educacional. Além dos dezoito núcleos urbanos, sedes de municípios, com escolas confessionais, estaduais e grupos escolares municipais nas principais vilas do interior, a população urbana passou a reivindicar outros níveis de escolarização, mais avançados (SILVA, 2011). 


\section{A educação rural no Brasil e no oeste paranaense}

A escola rural foi um fenômeno educativo que ganhou destaque em todas as regiões do Brasil na década de 1930 com a emergência de ideais ligadas a corrente de pensamento denominada de ruralismo pedagógico, cujos pressupostos centrais residiam na implantação de uma escola rural que considerasse as peculiaridades de cada região e deveria propiciar uma formação para o trabalho na terra, pois dela resultaria a subsistência para o homem do campo (THERRIEN, 1988). As primeiras tentativas de consolidação da educação rural se desenvolveram na sociedade brasileira como resultado do pujante movimento migratório interno dos anos 1910 e 1920. Com o êxodo rural e a procura por áreas onde se iniciava um processo de industrialização mais amplo, Adonia Antunes Prado (2000, p. 50) salienta que:

\footnotetext{
O ruralismo pedagógico apresentava-se como 'uma tendência de pensamento articulada por alguns intelectuais que formulavam ideias que já vinham sendo discutidas desde a década de 1920 e que resumidamente consistiam na defesa de uma escola adaptada e sempre referida aos interesses e necessidades hegemônicas do setor rural. Este pensamento privilegiava o papel da escola na construção de um 'homem novo', adaptado à nova realidade brasileira e de uma relação 'homem rural/escola' pretensamente nova.
}

As propostas do ruralismo pedagógico estavam alicerçadas num ideário que recusava a unificação do modelo escolar e preconizava um modelo de escola que se voltasse para atender às necessidades educacionais do campo como realidade sócio/cultural específica. A política destinada à educação rural tinha como principal objetivo aproximar a escola de tarefas práticas e das necessidades imediatas da população do campo. A essa ideia era acrescentada a concepção de que educar era fixar e adaptar o homem à terra (CALAZANS, 1993). Os pressupostos do ruralismo pedagógico estavam associados a uma ideia de que o valor da escola rural estava para além da ação educativa, ou seja, tinha a finalidade de realizar um trabalho cívico, patriótico e com fins econômicos (PRADO, 1995).

Na década de 1950, destacam-se a Campanha Nacional de Educação Rural (CNER) e o Serviço Social Rural (SSR), que desenvolveram projetos que visavam preparar professores com habilidades técnicas para educação rural e programas nas áreas de saúde, economia doméstica, artesanato e trabalho. Tanto a CNER como a SSR estavam à serviço de uma ideologia que propunha a modernização do campo por meio de ações assistencialistas. Tais programas criados para educação rural receberam forte influência de modelos educacionais dos Estados Unidos da 
América que tinham a intenção de integrar o camponês ao mercado de consumo. A origem da vertente estava no pensamento empresarial que previa o assistencialismo e o controle político sobre a terra e sobre as pessoas que viviam e dependiam dela (DAMASCENO; BESERRA, 2004).

O ideário do ruralismo pedagógico que vigorava em muitas regiões do país nesse período, procurava oferecer respostas às tensões sociais que resultavam do êxodo rural e do inchaço das cidades, que por sua vez, não estavam preparadas para absorver a mão de obra disponível. A educação foi utilizada como subsidiária de uma ideologia, qual seja: fixar o homem no campo, por meio da adaptação de programas e currículos ao meio rural que reforçavam os valores camponeses (LEITE, 1999).

O início do processo de escolarização do oeste paranaense se deu sob a égide do Estado Novo. As propostas governamentais de nacionalização das fronteiras e de difusão do Ensino Primário para todas as regiões do país exerceram papel importante na criação de escolas rurais na região. No período de sua ocupação, o oeste do Paraná era habitado principalmente por pessoas que viviam na área rural. O migrante que chegava à região buscava oportunidade de trabalhar na terra, comprar pequenos lotes e desenvolver a agricultura familiar.

Os núcleos urbanos eram criados e ao redor deles eram formados os povoados, com algumas famílias que desenvolviam atividades agrícolas de subsistência. Nessas localidades, o poder público e a iniciativa privada, sobretudo as igrejas, construíam escolas para atender aos filhos dos colonos em idade escolar. Nesse contexto, a Escola Rural de Xaxim foi criada mediante o "convênio celebrado entre o estado do Paraná e o Governo Municipal de Foz do Iguaçu” (PREFEITURA MUNICIPAL DE FOZ DO IGUAÇU, 1952, p. 1).

\section{A criação da escola rural de Xaxim (1952)}

Ao analisar a Escola Rural de Xaxim é necessário considerar o período de sua criação, início da década de 1950. Justino Magalhães diz que para a apreensão e explicação da realidade histórica de uma instituição escolar faz-se necessário integrá-la no sistema educativo mais amplo, na comunidade e na região onde ela desenvolveu e/ou desenvolve suas atividades (MAGALHÃES, 2004). 
Ao averiguar o cenário político e educacional da época, é possível perceber que o Brasil vivia um período de transição política e econômica. No campo político, o Governo de Getúlio Vargas (1882-1954), pautado pelo nacionalismo e pelo avanço econômico, voltou-se para o progresso econômico brasileiro por meio da expansão da indústria, fortalecimento da burguesia nacional e consolidação do capitalismo no país, à época, em processo de modernização. Essa visão de progresso provocou ondas migratórias do campo para as cidades, o que resultou num significativo aumento de trabalhadores na área urbana.

A educação escolar nesse período se voltou para a formação de sujeitos para o trabalho na cidade. No período, o Brasil passava por uma transição quanto à questão educacional. As Leis Orgânicas de Ensino, criadas em 1942, durante o Estado Novo, regulamentavam a educação escolar. A estrutura educacional do Estado Novo, "previu o ensino primário elementar com duração de quatro anos acrescido do primário complementar de apenas um ano" (SAVIANI, 2008, p. 269). A escola passou a ser vista como elemento essencial no processo de reconstrução da sociedade brasileira. Era defendida a necessidade de uma reorganização do ensino. A proposta era a difusão do Ensino Primário para todas as camadas da população brasileira. A ideologia educacional predominante foi a Escola Nova, até mesmo o ministro da educação do Governo Provisório, Francisco Campos (1891-1968), “[...] era integrante do movimento da Escola Nova” (SAVIANI, 2008, p. 195). Havia uma ênfase na atividade da escola como instrumento eficaz para a transformação social do país.

A Escola Rural de Xaxim foi criada nesse contexto geral de desenvolvimento industrial e econômico do Brasil e de expansão da educação escolar para todas as camadas da população como instrumento de crescimento econômico. A instituição surgiu para resolver o problema educacional daquela comunidade rural e também, atendeu aos interesses governamentais de expansão do ensino primário, especialmente para as regiões de fronteiras, que no período eram estratégicas do ponto de vista político e econômico.

Segundo consta da Ata Exames do primeiro ano funcionamento da escola, lavrada em 22 de dezembro de 1952, suas atividades tiveram início em 31 de março de 1952 (SECRETARIA MUNICIPAL DE EDUCAÇÃO E CULTURA DE FOZ DO IGUAÇU, 1952). Sua organização pode ser assim descrita: 


\subsection{Corpo docente}

Ao analisar a história de qualquer instituição educativa, não é possível fazê-la sem considerar os professores que nela atuaram, não é pertinente abdicar da análise referente à composição do seu corpo docente. A atuação dos professores na instituição, sua formação acadêmica e suas trajetórias são importantes no processo de reconstituição histórica de uma determinada escola. Analisar as trajetórias dos ex-professores é um eficiente mecanismo no processo para definir o sentido social da escola (NOSELLA; BUFFA, 2009).

$\mathrm{Na}$ área rural dos munícipios formados na região a partir de 1946, desenvolveu-se um modelo de educação escolar muito peculiar, cuja origem esteve diretamente associada à presença dos migrantes e a forma como, culturalmente, estes se organizaram em torno do ideário da educação e da escola. Esse modelo de instituição escolar é chamado por Emer (1991) de "Escola dos Colonos", um modelo de escola criado para servir ao grupo social e com características assemelhadas com a cultura e a cosmovisão deste determinado grupo. A escolha do professor envolvia uma série de questões importantes para o próprio grupo, afinal, seria a quem os migrantes confiariam seus filhos para formar homens e mulheres nas suas perspectivas de vida.

O perfil adequado do professor para escola dos colonos pode ser assim descrito: ter responsabilidade, entendida como frequência assídua ao trabalho todos os dias e pontualidade no horário; disposição para ensinar tudo que soubesse; autoridade moral de se fazer obedecer, por meio do exemplo pessoal; "ser de bem", ou seja, ter conduta social considerada adequada, exemplar, envolvendo aspectos ético-religiosos; frequentar uma igreja; ter bons modos nos encontros sociais da comunidade, entre outros (EMER, 1991).

Os colonos, ao escolherem os professores para a escola da comunidade, tinham o claro objetivo de perenizar, por meio da educação escolar, seus costumes, valores morais e crenças. Esperavam que seus filhos recebessem "boa formação" educacional, para tanto, a escolha do professor era essencial. Aqueles que eram indicados para dar aulas sempre aceitavam. Ser professor significava status perante a comunidade. Era uma função que além de oferecer uma boa remuneração, punha a pessoa numa posição social de proeminência em relação ao grupo. Muitos desses professores acabavam contratados pelo Poder Público e eram efetivados como professores da escola da comunidade. 
No caso da Escola Rural de Xaxim, a documentação registra a presença de uma única professora que atuou na instituição durante seu período de funcionamento. A professora Vilma Cerutti foi contratada pela Diretoria Geral da Educação de Foz do Iguaçu, em 24 de março de 1952, como pode ser verificado no documento a seguir na figura 1, e atuou na escola durante um período de nove anos (PREFEITURA MUNICIPAL DE FOZ DO IGUAÇU, 1952).

Figura 1: Contrato da professora Vilma Cerutti, 1952

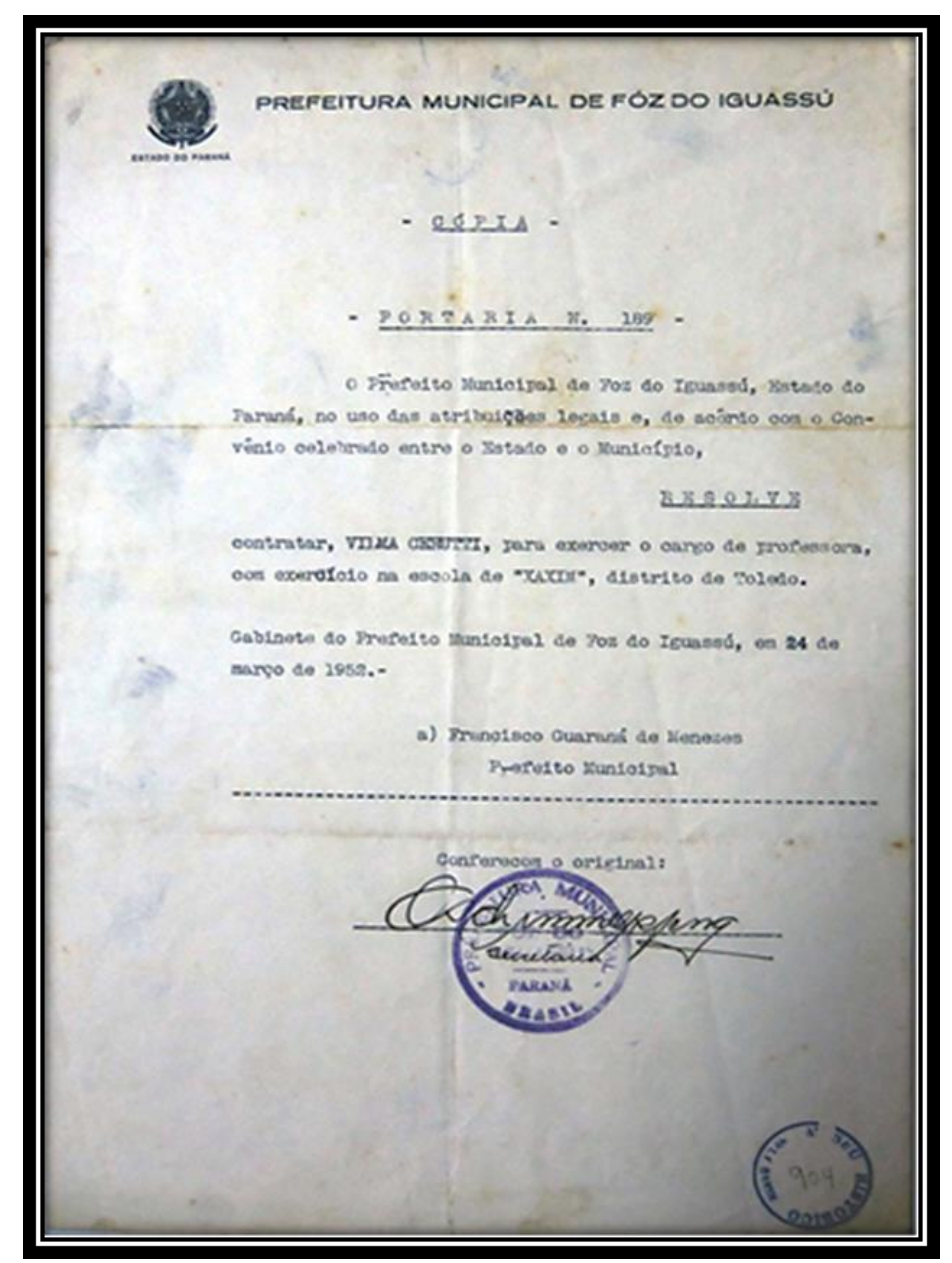

Fonte: Acervo do Museu Histórico Willy Barth, de Toledo, PR.

Em relação à formação acadêmica, a professora Vilma Cerutti tinha o Curso Normal, o que, à época, naquela região em vias de colonização, a diferenciava da maioria dos membros da comunidade. 


\subsection{Corpo discente e prédio escolar}

A análise da composição do corpo discente da Escola Rural de Xaxim, quando de sua implantação, assim como a origem social e o destino profissional de seus ex-alunos, contribuirá para aprofundar a compreensão da relevância social da instituição, bem como a proposta educacional que ela procurou oferecer a esse público. Como destaca Ester Buffa (2007), analisar a clientela que a escola atendeu pode servir de subsídio no processo de apreensão do formato de educação escolar que a instituição educativa desenvolveu.

Os alunos das primeiras turmas da instituição eram, em sua maioria, filhos de migrantes recém-chegados ao município de Toledo, oriundos do Oeste do Rio Grande do Sul e de Santa Catarina. A atividade econômica desses migrantes, em suas localidades de origem, era a agricultura. Ao chegarem ao oeste paranaense, eles tenderam a reproduzir seu modo de vida. Dessa maneira, a atividade econômica que desenvolveram no espaço colonial esteve associada ao cultivo da terra, isto é, à pecuária e, sobretudo, à policultura.

É importante destacar que, em relação ao gênero, na Escola Rural de Xaxim, meninos e meninas partilhavam da mesma sala de aula. À época, a separação das classes entre homens e mulheres era uma prática comum nas instituições educativas, especialmente nos grandes centros urbanos. Esse fato se evidencia quando da construção dos prédios escolares. Segundo Ester Buffa e Gelson Almeida Pinto (2002) nos grupos escolares era comum os edifícios serem divididos em duas alas, uma para meninos e outra para meninas. Até mesmo as entradas para esses ambientes eram independentes, visando à separação dos alunos por sexo. No estado do Paraná, foram criadas escolas exclusivas para atender o público feminino. Prevalecia a concepção de que a educação da mulher deveria ser inferior a do homem.

Não obstante ao fato do discurso sexista ainda imperar nas escolas das grandes cidades, nas atividades promovidas pela Escola Rural de Xaxim, todos participavam igualmente. A instituição optou pela coeducação, os migrantes seguindo o modelo utilizado em suas comunidades de origem, instituíram uma escola que atendia numa mesma classe, meninos e meninas.

Segundo consta da Ata de Exames finais do ano de 1952, documento elaborado pelas examinadoras Irmã Helena e Irmã Aracy Mendes, para a Secretaria de Educação e Cultura do município de Foz do Iguaçu no dia 22 de dezembro, a escola terminou seu primeiro ano letivo 
com um total de 21 alunos, todos residentes no povoado de Xaxim (ESCOLA RURAL DE XAXIM, 1952). Em 1952, a instituição iniciou suas turmas da seguinte forma, de acordo com o quadro 1:

Quadro 1 - Escola Rural de Xaxim (1952)

\begin{tabular}{|c|c|c|c|}
\hline Série/turma & Sexo masc. & Sexo fem. & Total de alunos \\
\hline $1^{\mathrm{a}}$ série & 05 & 04 & 09 \\
\hline $2^{\mathrm{a}}$ série & 04 & 04 & 08 \\
\hline $3^{\mathrm{a}}$ série & 02 & 02 & 04 \\
\hline Total & & & 21 \\
\hline
\end{tabular}

Fonte: Acervo do Museu Histórico Willy Barth, de Toledo, PR.

Conforme consta dos livros de matrículas, de 1952 e 1953, a profissão dos pais dos primeiros alunos da instituição pode ser assim relacionada: agricultores - pequenos proprietários de terras; pequenos comerciantes; profissionais liberais: mecânicos, carpinteiros, marceneiros e ferreiros. Esses dados revelam a origem social e econômica do público que a escola atendeu e, por conseguinte, as funções que esses alunos ocupariam naquela sociedade. Trata-se de uma clientela típica da área rural de uma região de colonização recente, onde as famílias de migrantes, recém-chegado à localidade, tinham como preocupação primeira providenciar as condições mínimas para sua subsistência e, posteriormente se encarregar da educação de seus filhos, por isso, os investimentos nas questões relativas à educação escolar só se tornaram prioritárias após o definitivo estabelecimento dos migrantes na região.

Deste modo, em seus primeiros anos, a Escola Rural de Xaxim desenvolveu suas atividades educacionais numa sala cedida pela Igreja Católica. O prédio era construído em madeiras e albergava todos os alunos numa única sala de aula (SECRETARIA MUNICIPAL DE EDUCAÇÃO E CULTURA DE FOZ DO IGUAÇU, 1952).

As estruturas prediais de uma escola revelam importantes características de sua história e até mesmo, aspectos da educação desenvolvida por ela e podem ser considerados como documentos no processo de reconstituição histórica de uma escola, pois existem neles relações de poder e relações de caráter educativo. Embora a arquitetura não defina a filosofia educacional de 
uma instituição, quando é adequada, contribui para a maximização das finalidades pedagógicas.

Entende-se que informações relevantes sobre a trajetória e mesmo as propostas educacionais de uma escola, podem estar aninhadas na arquitetura escolar. Como transmissão silenciosa, a arquitetura veicula os símbolos de cada momento histórico e também, revelam a realidade de seu entorno. Justino Magalhães afirma que para a construção do prédio escolar há que considerar importantes aspectos, tais como: localização, projeção e plano arquitetônico, processo de licenciamento, enquadramento paisagístico e urbanístico e tipo de construção, organização dos espaços, estado de conservação, adaptações arquitetônicas e espaciais, pois, a implantação do edifício na paisagem física e humana, os acessos e formas de isolamento e de relação refletem, condicionam ou estimulam a relação com a comunidade envolvente (MAGALHÃES, 2004). A fotografia abaixo retrata as condições materiais do primeiro prédio da instituição.

Figura 2 - Foto da primeira turma da Escola Rural de Xaxim em 1952

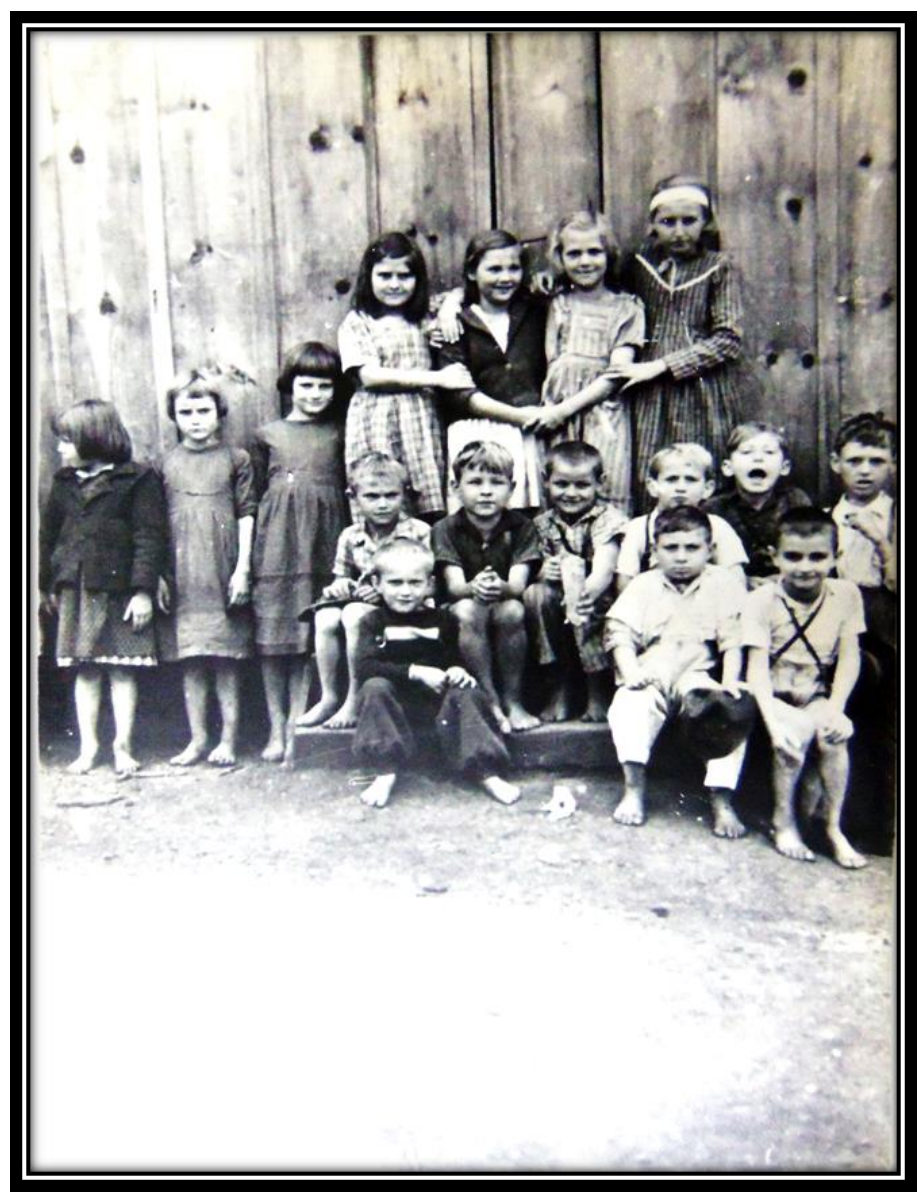

Fonte: Museu Histórico Willy Barth, de Toledo, PR. 
Pode-se notar na fotografia acima, a simplicidade do prédio escolar, construído em madeiras como era comum no período em regiões de ocupação recente. A materialidade do espaço-escola bem como seus elementos simbólicos próprios ou incorporados formam um constructo cultural que expressa e reflete sentidos e significados que expressam a realidade da sociedade na qual a instituição educativa está inserida.

Os alunos da Escola Rural de Xaxim, como pode ser observado na imagem, estavam vestidos com roupas simples e sem calçados, retratando que a escola era para eles uma extensão de suas casas. Tratava-se de crianças oriundas de famílias camponesas, que vieram para reproduzir sua condição de colonos na região oeste do Paraná, como trabalhadores rurais.

\subsection{Currículo}

O currículo pode ser entendido como a vivência de experiências sistematicamente organizadas e planejadas com o objetivo de atingir o ensino e a aprendizagem de elementos culturais, selecionados e institucionalmente considerados relevantes para que os alunos atinjam o nível de formação previsto. O currículo constitui-se numa prática social complexa, construída historicamente, a partir de relações sociais, políticas e econômicas; por isso, não se restringe apenas às questões internas das instituições educativas, mas sua configuração recebe influência do contexto geral da sociedade.

$\mathrm{Na}$ análise de um currículo escolar pode-se identificar influências de ordem política, social, econômica e cultural; um sistema social integral que funciona e se desenvolve segundo leis específicas, na base de um respectivo modo de produção que compreende um processo histórico de um determinado tipo de sociedade historicamente construída (BITTAR; FERREIRA JR., 2009). Nesse sentido, o currículo não se restringe apenas às questões internas das instituições educativas, mas sua configuração recebe influência do contexto geral.

O currículo é um instrumento de ação política; é uma ação coletiva que se fundamenta numa concepção de mundo, de homem e de educação; deve ser concebido como um artefato cultural e histórico, pensado e repensado ao longo da história, a partir de conflituosas relações de poder. Logo, ele é muito mais que um rol de disciplinas e conteúdos, é uma questão políticocultural pelo fato de carregar intenções e ideologias que conduzem atitudes frente às relações sociais. De acordo com Miguel Arroyo (2007, p. 4), 
Os currículos não são conteúdos prontos a serem repassados aos alunos. São uma construção e uma seleção de conhecimentos, valores, instrumentos da cultura produzidos em contextos e práticas sociais e culturais. Daí a preocupação em recuperar, nos currículos, a estreita relação entre conhecimento e cultura. Essas questões estão em debate no terceiro programa da série.

A Escola Rural de Xaxim, conforme consta da documentação, tinha a seguinte grade curricular: Linguagem; Ciências Sociais; História; Matemática e Trabalhos Manuais (ESCOLA RURAL DE XAXIM, 1952). A instituição funcionou num modelo de classe multisseriada, que correspondia à junção de várias séries em uma única sala de aula. Nesse modelo, o professor dividia o quadro em quantas partes fossem necessárias para atender às séries existentes na classe (CAPELO, 2000).

O modelo de classes multisseriadas foi amplamente utilizado no sistema educacional brasileiro desde o século XIX. Especialmente as escolas rurais tiveram que adequar seu ensino a este formato. A educação rural multisseriada deveria ser uma educação específica e diferenciada, elaborada com vistas à formação humana, emancipadora e criativa, deveria adotar de fato a identidade do meio rural.

\section{Considerações finais}

A análise dos dados revelados pelas fontes aponta que a história da instalação da Escola Rural de Xaxim esteve diretamente relacionada com o processo de escolarização da região oeste do Paraná e do município de Toledo. A instituição foi criada mediante um convênio entre o estado do Paraná e a Prefeitura municipal de Foz do Iguaçu, que, à época, era a Comarca de Toledo. Como escola rural, a instituição foi formada para atender aos filhos dos trabalhadores rurais que residiam no Povoado de Xaxim.

Ela fez parte do ideário do ruralismo pedagógico que vigorava em muitas regiões do Brasil no período de sua implantação, cuja premissa principal era que o valor da escola rural estava para além de sua ação educativa, sua finalidade era realizar um trabalho cívico, patriótico e com fins econômicos. A educação nesta perspectiva possuía uma função estratégica, qual seja: incentivar a permanência do homem no campo e reforçar os valores camponeses por meio da adaptação de programas e currículos para o meio rural.

As práticas educativas da instituição não destoaram das Políticas Educacionais vigentes naquele período, que propunham a difusão e a consolidação do ensino primário para todas as 
regiões brasileiras. O contexto político e educacional em que a escola foi criada concebia a educação escolar como elemento essencial para o processo de reconstrução da sociedade e defendia a necessidade de uma reorganização do ensino.

As atividades da escola estiveram alinhadas ao projeto de nacionalização da educação que vigorou no Brasil durante as décadas de 1930 a 1950. Tais medidas foram coerentes com o cenário político/econômico e social que imperava no país naquele momento, ajustado ao contexto internacional. Neste sentido, a Escola Rural de Xaxim, mesmo que de modo não intencional, cumpriu o papel de consolidar o discurso do Governo Federal e se adequou às novas forças produtivas, que exigiam a modernização das relações de produção e acabou por cumprir uma tarefa de preparar trabalhadores que colaboraram com o projeto de nacionalização do oeste paranaense e de consolidação do ensino público na região.

\section{Referências}

ARÓSTEGUI, Júlio. A pesquisa histórica: teoria e método. Bauru: EDUSC, 2006.

ARNAUT DE TOLEDO, Cézar de Alencar; ANDRADE, Rodrigo Pinto de. História e historiografia da Escola Lutera Concórdia de Marechal Cândido Rondon (1955-1969). In: SILVA, João Carlos da et al. (Org.). História da educação: arquivos, instituições escolares e memória histórica. Campinas: Alínea, 2013. p. 191-210.

ARROYO, Miguel. Educadores e educandos, seus direitos e o currículo. Salto Para o Futuro: boletim, Brasília, n. 17, p. 7-11, set. 2007.

BITTAR, Marisa; FERREIRA JR., Amarilio. História, epistemologia marxista e pesquisa educacional brasileira. Educação \& Sociedade, Campinas, v. 30, n. 107, p. 489-511, 2009.

BOSI, Alfredo. Dialética da colonização. São Paulo: Companhia das Letras, 1992.

BUFFA, Ester. Os estudos sobre instituições escolares: organização do espaço e propostas pedagógicas. In: NASCIMENTO, Maria Isabel Moura et al. Instituições escolares no Brasil: conceito e reconstrução histórica. Campinas: Autores Associados, 2007. p. 151-164.

BUFFA, Ester; PINTO, Gerson Almeida. Arquitetura e educação: organização do espaço e propostas pedagógicas dos grupos escolares paulistas, 1893/1971. São Carlos: EdUFSCar, 2002.

CALAZANS, M. J. Educação no meio rural. Educação e escola no campo. Campinas: Autores Associados, 1993.

CAPELO, Maria Regina Clivati. Educação, escola e diversidade cultural no meio rural de Londrina: quando o presente reconta o passado. 2000. 287f. Tese (Doutorado em Educação, Sociedade e Cultura) Universidade Estadual de Campinas, Campinas, 2000.

DAMASCENO, Maria Nobre; BESERRA, Bernadete. Estudos sobre educação rural no Brasil: estado da arte e perspectivas. Educação e Pesquisa, São Paulo, v. 30, n. 1, p. 73-89, jan./abr. 2004. Disponível em: < file:///C:/Users/RODRIGO/Desktop/Educa\%C3\%A7\%C3\%A3o\%20Rural.pdf>. Acesso em: 6 abr. 2015.

Quaestio, Sorocaba, SP, v. 19, n. 1, p. 47-68, abr. 2017. 
EMER, Ivo Oss. Desenvolvimento histórico do oeste do Paraná e a construção da escola. 1991. $340 f$. Dissertação (Mestrado em Educação) - Programa de Pós-Graduação em Educação, Fundação Getúlio Vargas, Rio de Janeiro, 1991.

ESCOLA RURAL DE XAXIM. Livro-ata: exames finais do ano letivo de 1952 da Escola Rural de Xaxim. Toledo: [Arquivo do Museu Histórico Willy Barth], 1952. 02 f.

FERREIRA JR., Amarilio; BITTAR, Marisa. Educação e ideologia tecnocrática na ditadura militar. Cadernos Cedes, Campinas, v. 28, n. 76, p. 333-355, set./dez. 2008. Disponível em: <http://www.cedes.unicamp.br>. Acesso em: 12 mai. 2011.

GATTI JR., Décio. História das instituições educacionais: inovações paradigmáticas e temáticas. In: ARAÚJO, José Carlos Souza; GATTI JR., Décio. (Org.). Novos temas da educação: instituições escolares e educação na imprensa. Campinas: Autores Associados; Uberlândia: EDUFU, 2002. p. 3-24.

GREGORY, Valdir. Os eurobrasileiros e o espaço colonial: migrações no oeste paranaense. Cascavel: EDUNIOESTE, 2005.

LE GOFF, Jacques. História e Memória. Campinas: Editora da Unicamp, 2003.

LEITE, S. C. Escola rural: urbanização e políticas educacionais. São Paulo: Cortez, 1999.

LOMBARDI, José Claudinei. Educação e ensino na obra de Marx e Engels. Campinas: Alínea, 2011.

MAGALHÃES, Justino Pereira de. Da cadeira ao banco: escola e modernização (séculos XVIII-XX). Lisboa: EDUCA, 2010.

MAGAlHÃES, Justino Pereira de. Tecendo Nexos: história das instituições educativas. Bragança Paulista: EDUSF, 2004.

MAGALHÃES, Justino Pereira de. Um apontamento metodológico sobre a história das instituições educativas. In: SOUSA, Cynthia Pereira de; CATANI, Denice Bárbara. (Org.). Práticas educativas, culturas escolares, profissão docente. São Paulo: Escrituras, 1998.

MARX, Karl; ENGELS, Friedrich. A ideologia alemã (I- Feuerbach). 9. ed. São Paulo: HUCITEC, 1993.

NIEDERAUER, Ondy Hélio. Toledo no Paraná: a história de um latifúndio improdutivo, sua reforma agrária, sua colonização, seu progresso. 2. ed. Toledo: Tolegraf, 2004.

NOSELLA, Paolo; BUFFA, Ester. Instituições escolares: por que e como pesquisar. Campinas: Alínea, 2009.

NOSELLA, Paolo; BUFFA, Ester. As pesquisas sobre instituições escolares: o método dialético marxista de investigação. In: ARAUJO, Ronaldo Marcos de Lima; RODRIGUES, Doriedson (Org.). Trabalho, educação e políticas educacionais. São Paulo: Alínea, 2012. p. 131-146.

PRADO, Adonia Antunes. Intelectuais e educação no Estado Novo (1937-1945): o debate sobre a formação do professor primário rural. Teias, Rio de Janeiro, v. 1, n. 1, p. 46-55, jan./jun. 2000.

PRADO, Adonia Antunes. Ruralismo pedagógico no Brasil do Estado Novo. Estudos Sociedade e Agricultura, Rio de Janeiro, n. 4, p. 5-27, 1995.

PREFEITURA MUNICIPAL DE FOZ DO IGUAÇU. Contrato da professora Vilma Cerutti pela Diretoria Geral de Educação do Município de Foz do Iguaçu. Toledo: [Arquivo do Museu Histórico Willy Barth], 1952. $01 \mathrm{f}$.

RAGAZZINI, Dário. Para quem e o que testemunham as fontes da história da educação? Educar em Revista, Curitiba: Editora da UFPR, n. 18, p. 13-28, jul./dez. 2001. 
SANFELICE, José Luís. História das instituições escolares. In: NASCIMENTO, Maria Isabel Moura et al. (Org.). Instituições escolares no Brasil: conceito e reconstrução histórica. Campinas: Autores Associados, 2007. p. 75-93.

SAVIANI, Dermeval. História das ideias pedagógicas no Brasil. 2. ed. rev. e ampl. Campinas: Autores Associados, 2008.

SAVIANI, Dermeval. Breves considerações sobre as fontes para a história da educação. In: LOMBARDI, José Claudinei; NASCIMENTO, Maria Isabel Moura (Org.). Fontes, história e historiografia da educação. Campinas: Autores Associados, 2004. p. 3-12.

SCHNEIDER, Claércio Ivan. Os senhores da terra: produção de consensos na fronteira. (Oeste do Paraná, 1946-1960). 2001. 157 f. Dissertação (Mestrado em História) - Programa de Pós-Graduação em História, Universidade Estadual do Paraná, Paranavaí, 2001.

SECRETARIA MUNICIPAL DE EDUCAÇÃO E CULTURA. Boletim mensal do mês de março de 1952 da Escola Rural de Xaxim. Toledo: [Arquivo do Museu Histórico Willy Barth], 1952. 01 f.

SILVA, João Carlos da. A escola publica primária na região oeste do Paraná: levantamento de fontes e produção acadêmica. EccoS, São Paulo, n. 26, p. 123-140, jul./dez. 2011.

THERRIEN, J. Políticas de educação para o meio rural: o papel do estado e a produção do saber. In: CONGRESSO BRASILEIRO DE EDUCACÃO, 4., São Paulo. Anais... São Paulo: Cortez, 1988. p. 171197.

WACHOWICZ, Christovam Ruy. História do Paraná. Curitiba: Imprensa Oficial do Paraná, 2001.

WACHOWICZ, Christovam Ruy. Obrageros, mensus e colonos: história do oeste paranaense. Curitiba: Vicentina, 1982.

Francielle Aparecida Garuti de Andrade - Universidade Estadual de Maringá - UEM. Maringá | PR | Brasil. Contato: garuti_andrade@yahoo.com.br

Cézar de Alencar Arnaut de Toledo - Universidade Estadual de Maringá - UEM. Maringá | PR | Brasil. Contato: caatoledo@uem.br 